\title{
Surgical Sutures with Porous Sheaths for the Sustained Release of Growth Factors
}

\author{
By Jianhua Li, Stephen W. Linderman, Chunlei Zhu, Hong Liu, Stavros Thomopoulos, and Younan
}

\author{
Xia*
}

[*] Prof. Y. Xia, J. Li., Dr. C. Zhu

The Wallace H. Coulter Department of Biomedical Engineering, Georgia Institute of Technology and Emory University, Atlanta, GA 30332 (USA)

Prof. Y. Xia

School of Chemistry and Biochemistry, School of Chemical and Biomolecular Engineering, Georgia Institute of Technology, Atlanta, GA 30332 (USA)

Prof. S. Thomopoulos

Department of Orthopaedic Surgery

Department of Biomedical Engineering

Columbia University, New York, NY 10032 (USA)

S. W. Linderman

Department of Biomedical Engineering

Department of Orthopaedic Surgery

Washington University in St. Louis, St. Louis, MO 63130 (USA)

Prof. H. Liu, J. Li

State Key Laboratory of Crystal Materials

Shandong University, Jinan, Shandong 250100 (P. R. China)

E-mail: younan.xia@bme.gatech.edu (for sample preparation); and sat2@columbia.edu (for mechanical testing)

[**] This work was supported in part by a grant from the National Institutes of Health (R01 AR060820 and R01 AR062947) and startup funds from the Georgia Institute of Technology (to Y.X.). As a jointly supervised Ph.D. candidate from Shandong University, J. L. was also partially supported by a fellowship from the China Scholarship Council.

This is the author manuscript accepted for publication and has undergone full peer review but has not been through the copyediting, typesetting, pagination and proofreading process, which may lead to differences between this version and the Version of Record. Please cite this article as doi: 10.1002/adma.201506242.

This article is protected by copyright. All rights reserved. 
Supporting information for this article is available on the WWW under http://dx.doi.org/.

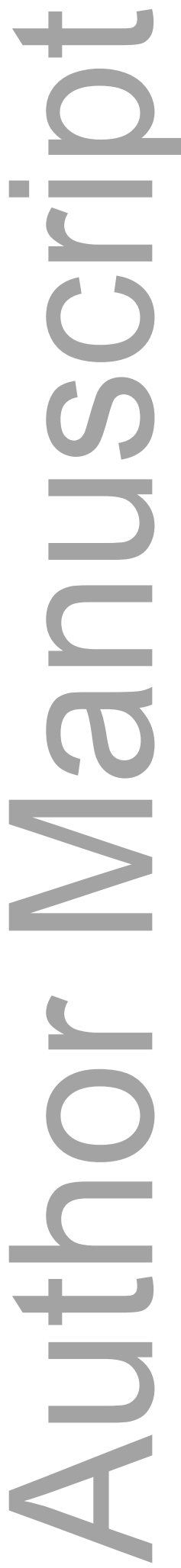

This article is protected by copyright. All rights reserved. 


\begin{abstract}
A simple method was developed for modifying commercially available sutures to improve the delivery of growth factors. We demonstrated that micrometer-sized pores could be generated in the sheath of a cable-type suture through a swelling and freeze-drying process. Tensile testing indicated that the modification process did not compromise the mechanical integrity of the suture, as the inner filaments remained intact. The capillary action caused by the porous structure greatly enhanced the loading of biofactors into the void space among the filaments. We also demonstrated that a sustained and controlled release of platelet-derived growth factor-BB (PDGF) from the modified sutures could be achieved using fibrin as a carrier material. The PDGF released from the modified sutures retained its biologic activity and supported the proliferation of human mesenchymal stem cells. This novel class of surgical sutures with highly porous sheaths offers a promising platform for enhancing the repair of load bearing connective tissues.
\end{abstract}

Keywords: suture, drug delivery, sustained release, tendon repair

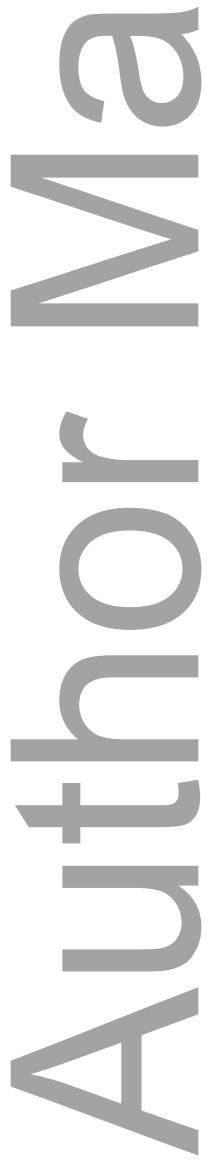

This article is protected by copyright. All rights reserved. 
Surgical sutures with highly porous sheaths were developed using a swelling and freeze-drying procedure without compromising their mechanical properties. The modified sutures showed a high capacity for loading biofactors and were able to release the loaded biofactors in a sustained manner.
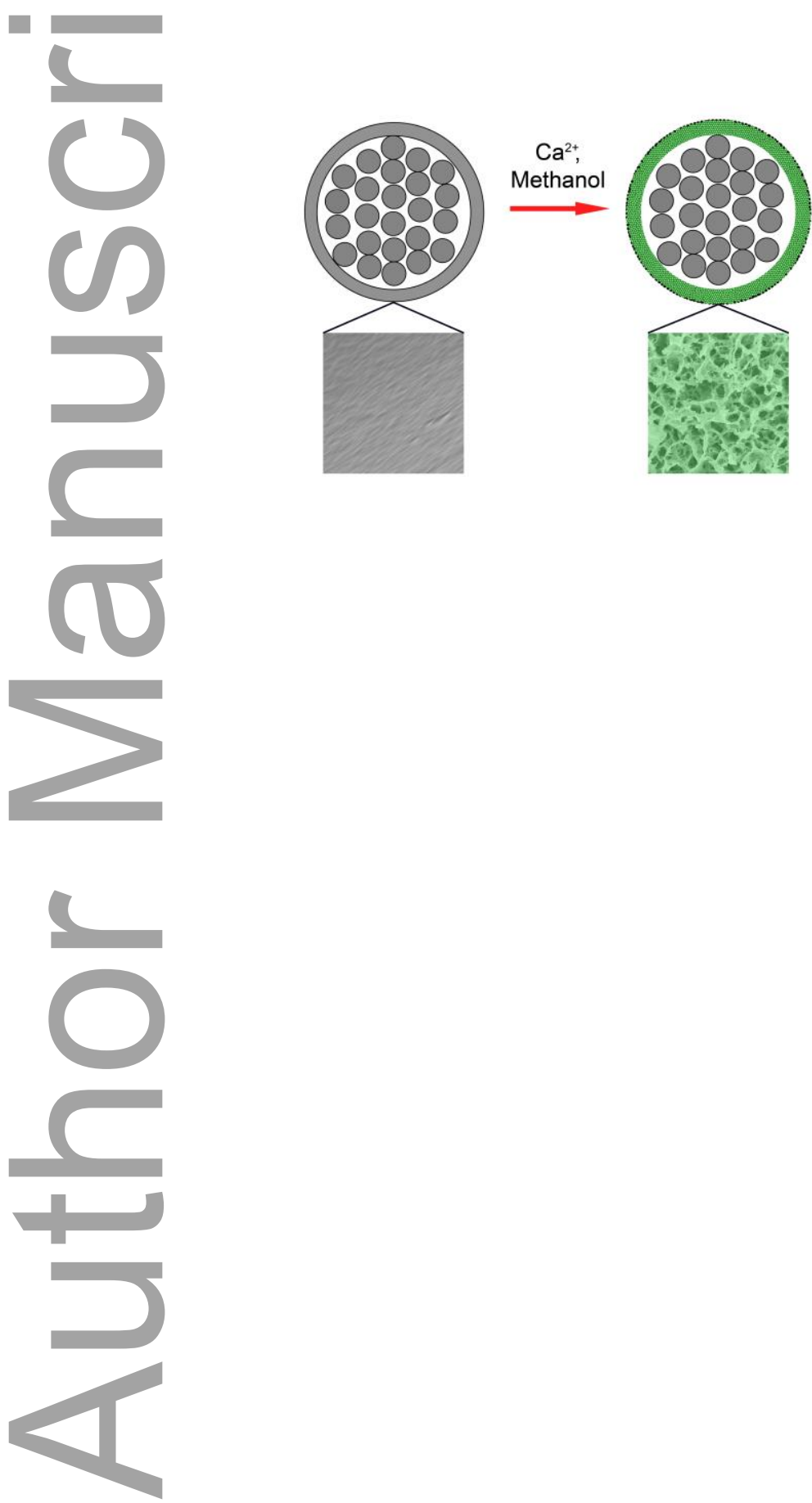

This article is protected by copyright. All rights reserved. 
Surgical repair of connective tissues such as tendons remains a clinical challenge, primarily due to the failure for the injured site to restore strength within the first three weeks. ${ }^{[1,2]}$ There are attempts to improve the outcome by increasing the strength of the suture material and modifying the suture grasping method. Although these approaches can improve the initial strength of the repair, they cannot regulate the subsequent biology of healing. In comparison, the tissue engineering strategy, including the use of growth factors, stem cells, and/or scaffolds, provides a great opportunity to improve the efficacy of repair. Specifically, sustained delivery of growth factors to the injured site offers an important strategy for controlling the healing process, which is directed by a complex cascade of biological events modulated by a set of cytokines and growth factors such as plateletderived growth factor (PDGF), vascular endothelial growth factor (VEGF), transforming growth factor ß (TGF-ß), and basic fibroblast growth factor (bFGF). ${ }^{[3-6]}$

Sutures are ideal delivery vehicles for biofactors because they are ubiquitously used to provide initial mechanical support for the repair site. Prior work on local delivery of biofactors via sutures has primarily focused on coating the surface of a solid suture thread with a biofactor or biofactorcontaining material. ${ }^{[7-12]}$ One major disadvantage of this coating strategy is that almost all of the biofactors are exposed to the surrounding tissue, resulting in the quick release of a large portion of the biofactor within the first few hours after implantation. Sustained release of biofactors from sutures can be achieved using various types of carriers, but most of the reported release profiles remain relatively short. ${ }^{[10-12]}$ For example, using a carrier based on fatty acid, antiseptic release from braided sutures was only achieved over a period of 100 hours. ${ }^{[10]} \mathrm{A}$ second disadvantage of directly coating the surface of a suture is that the amount of biofactor that can be loaded is rather limited. Typically, the biofactor is restricted to a thin coating layer, and the coating can easily peel off during handling due to weak binding between the coating layer and the suture surface. Despite these prior efforts and some marginal success in enhancing tendon healing with biofactor-loaded sutures, ${ }^{[10-12]}$ there is still a great potential for increasing the dose and time course of suture-based biofactor delivery.

In the present work, we aim to modify commercially available sutures for improved delivery of growth factors by achieving efficient loading and sustained release of growth factors without compromising the mechanical integrity of the suture. Specifically, cable-type sutures were partially swollen and then freeze-dried to generate micrometer-sized pores in the sheaths. We focused on a class of commercially available polyfilament sutures commonly used for tendon repair. ${ }^{[13,14]}$ The suture is characterized by a cable-type structure consisting of fine inner nylon-66 filaments enclosed by a nylon- 6 sheath with a smooth surface. After modification, the sheath became highly porous 
while the inner filaments remained intact. As such, the voids among the inner filaments could be fully accessed and employed for the loading of biofactors while the porous sheath could serve as a physical barrier to slow down the subsequent release process.

Figure S1, $a$ and $b$, shows a schematic illustration of the procedure, which involves swelling and then freeze-drying the suture. In the first step, the sutures were swollen in a methanol $\left(\mathrm{CH}_{3} \mathrm{OH}\right)$ solution containing calcium chloride $\left(\mathrm{CaCl}_{2}\right)$. The $\mathrm{Ca}^{2+}$ ions formed coordination bonds with the carbonyl groups on nylon, breaking the hydrogen bonds between adjacent nylon chains. ${ }^{[15]}$ By controlling the incubation time, we were able to restrict most of the swelling to the sheaths only before the $\mathrm{Ca}^{2+}$ ions started to attack the inner filaments. To confirm this, the distribution of calcium in a modified suture was characterized by EDX mapping. As shown in Figure S1c, most of the calcium was confined to the sheath. In the next step, the swollen sutures were quickly frozen by transferring them into liquid nitrogen $\left(-196^{\circ} \mathrm{C}\right)$. The solvent molecules trapped in the sheaths were crystallized and phase-separated from the polymer chains, eventually producing a highly porous structure once the solvent molecules had been removed by sublimation. ${ }^{[16-18]}$ The final products were sutures with highly porous sheaths and intact inner filaments.

Figure 1 shows typical scanning electron microscopy (SEM) images of the sutures before and after the modification. The original cable-type structure was retained during the modification, with packed filaments bundled by an outer sheath with a thickness of $\sim 10 \mu \mathrm{m}$ (Figure 1 , a and b). The pristine suture showed smooth surfaces. In contrast, the modified suture had a highly porous surface, with pore sizes in the range of $0.5-5 \mu \mathrm{m}$ (Figure 1, c and d). The micrometer-sized pores were generated through the entire cross-section of the sheath (Figure S2). By varying the $\mathrm{Ca}^{2+}$ concentration, we were able to control both the porosity and pore size (Figure S3). Since the inner filaments are the major contributors to the mechanical properties of a suture, our initial goal was to avoid modifying these inner filaments. Indeed, there were very few pores on the surfaces of the inner filaments.

We then evaluated the mechanical properties of the sutures, with and without modification, and the results are shown in Figure 2. The two groups of stress-strain curves show similar patterns, indicating that the modification did not have a substantial impact on the mechanical properties of the sutures. There was no significant difference in modulus when comparing the pristine and modified sutures. The moduli were $1.49 \pm 0.03 \mathrm{GPa}$ and $1.59 \pm 0.13 \mathrm{GPa}$ for the pristine and modified sutures, respectively. The maximum stress increased slightly, from $506.6 \pm 17.2 \mathrm{MPa}$ for the pristine sutures to $530.4 \pm 14.5 \mathrm{MPa}$ for the modified sutures $(p<0.05)$, likely due to the formation of $\mathrm{Ca}^{2+}$-nylon 6 complex. ${ }^{[15]}$ The strain at maximum stress and the yield strain of the 
modified sutures also increased by $c a .16 \%$ when compared to the pristine sutures $(p<0.05)$. As expected, the lack of modification to the inner filaments of the suture resulted in retention of mechanical properties, despite the creation of pores in the outer sheath.

A major objective of this study was to increase the amount of a biofactor that could be loaded into a suture. Upon modification, infiltration of biofactor molecules into the voids among the inner filaments could be readily achieved via the interconnected pores created in the sheath. To validate the loading mechanism, we used a water-soluble dye (Rhodamine B) and a dye-labeled protein (FITC-BSA) as model systems of small and large molecules, respectively, to compare the pristine and modified sutures. Figure 3 shows fluorescence micrographs of the cross-sections of loaded sutures. Both the dye and dye-labeled protein could be clearly observed inside the modified suture, filling the void space among the filaments. For the pristine sutures, however, even the small dye molecules could only be observed on the outer surface. This result indicates that the dense sheath surrounding the filaments in the pristine sutures could not be easily penetrated by molecular species, whereas the highly porous sheath of the modified sutures could be used to access the voids among the inner filaments for the quick loading of even macromolecules. In the modified suture, the capillary effect resulting from the interconnected pores and the concentration gradient of molecules in the solution effectively drove these molecules through the pores and into the voids inside the sutures (Figure 3, e and f). The capillary action caused by the porous structure enhanced the loading of biofactors into the sutures. A simple demonstration of this capillary effect is shown in Figure S4. Quantification of the released dye demonstrated a nearly four-fold increase of dye loading for the modified sutures compared to the pristine sutures (Figure S5). Furthermore, the integrity of the porous sheath was demonstrated by the retention of loaded dye in modified sutures that were passed through a bovine tendon ten times (Figure S6).

A second major objective of this study was to release biofactors in a sustained manner from sutures. We expected that the porous sheath on the modified suture, which allowed the biofactors to infiltrate into the suture through capillary action, could also serve as a physical barrier to slow the subsequent release process. To demonstrate this, we used recombinant human PDGF as a model growth factor and fibrin as a carrier material. PDGF promotes chemotaxis and mitogenesis of mesenchymal cells, including tendon fibroblasts and mesenchymal stem cells. ${ }^{[19-21]}$ PDGF has been successfully used to promote tendon healing, including enhancing the collagen organization, mechanical function, and vascularity. ${ }^{[4,22,23]}$ Fibrin was used as a carrier material owing to its current clinical acceptance and the interactions it can have with endogenous factors, such as PDGF, TGF- $ß$ and VEGF, among others. ${ }^{[24]}$ To determine the release characteristics of the growth factor from the 
modified sutures, PDGF $(10 \mu \mathrm{g} / \mathrm{mL}$ ) was loaded into the sutures together with fibrin (see Figure S7 for a typical SEM image of the surface of a modified suture after fibrin loading). Figure 4 shows the cumulative release of PDGF from the modified sutures as determined over a period up to 11 days. The release kinetics can be described using a two-stage model. The first stage shows a burst release and the second stage is characterized by a sustained release. For the first stage, approximately $38 \%$ of the loaded growth factor was released within the first 24 hours for modified sutures. In contrast, $81 \%$ of the growth factor was released from the pristine sutures within only 24 hours. In the second stage of release, for modified sutures, the growth factor (presumably trapped in the spaces among the inner filaments) was released through the fibrin network via the porous sheath in a sustained manner from day 2 to day 11 . Furthermore, the total released growth factor from the modified sutures, that is, the dosage, was linearly dependent on the initial concentration of PDGF used for lading, in the range of $50 \mathrm{ng} / \mathrm{mL}$ to $10 \mu \mathrm{g} / \mathrm{mL}$ for this study $\left(\mathrm{R}^{2}=0.99 ; \mathrm{n}=3\right.$ for each group). Delivery of growth factors at specific dosages within the first three weeks is critical for tendon healing. Therefore, the sustained and controlled release of biofactors from sutures presented here has a great potential for enhancing tendon repair.

To evaluate potential cytotoxity of the modified sutures and the PDGF-loaded modified sutures, human mesenchymal stem cells (hMSCs) were cultured on and around sutures and viability was assessed after $72 \mathrm{~h}$. As shown in Figure 5, the hMSCs were viable after culture, indicating that the effects of any remaining chemicals during the preparation of porous sutures were negligible. To verify that the loading/release processes did not alter the bioactivity of the released growth factor, hMSCs were cultured in the presence of $10 \mathrm{ng} / \mathrm{mL}$ PDGF and PDGF-loaded sutures (Figure S8). The results indicate that the released PDGF retained its biologic activity and supported the proliferation of hMSCs. Recent reports have successfully demonstrated the potential for combinatory use of growth factors (e.g., bFGF and PDGF) and stem cells (e.g., adipose-derived mesenchymal stem cells and bone marrow stromal cells) for tendon repair in vivo. ${ }^{[25,26]}$ The suture-based release of these growth factors would simplify the delivery of these factors alone or in combination with stem-cell therapies for more effective tendon repair.

In summary, we have developed a simple and versatile method for generating surgical sutures with highly porous sheaths without compromising their mechanical properties. The capability of this method could also be extended to generate pores on the surface of monofilament sutures (Figure S9). The modified sutures showed a great improvement in loading capacity and a sustained release of biologically active PDGF over a period of at least 11 days. This novel delivering system based on porous sutures has great potential for the repair of load-bearing connective tissues such as tendons.

This article is protected by copyright. All rights reserved. 
Additionally, it can be readily extended to other applications, including the delivery of antimicrobials after wound closure and long-term pain relief post-surgery.

\section{Experimental Section}

Preparation of Modified Sutures. Pristine sutures (Supramid 4-0, cable-type) were purchased from S. Jackson Inc. (Alexandria, VA). The inner filaments are made of nylon 66 while the sheath is comprised of nylon 6 . Sutures with porous sheaths were prepared using a swelling and freeze-drying procedure. Briefly, the pristine sutures were cut into a certain length and soaked in a $500 \mathrm{mM} \mathrm{CaCl}$ solution in methanol for $24 \mathrm{~h}$ at room temperature. Afterwards, the swollen sutures were quickly frozen in liquid nitrogen and then freeze-dried in a vacuum overnight. Since all the reagents used in this process are water-soluble, their residues could be readily removed by rinsing the samples with water.

Mechanical Testing. The pristine and modified sutures were pulled in uniaxial tension using a material testing machine (5866; Instron Corp.), as described previously. ${ }^{[27]}$ A suture was carefully placed in a jig consisting of a low friction spool and a clamp grip, which was pulled upward at 1.0 $\mathrm{mm} / \mathrm{s}$ to apply tension to the suture. The gauge length between the suture grips was $110 \mathrm{~mm}$ for all the samples at the beginning of the test. Maximum stress, yield strain, strain at maximum stress, and modulus were determined from the stress-strain curves.

Preparation and Characterization of Biofactor-loaded Sutures. The biofactor-loaded sutures were prepared in a biological safety cabinet and all the solutions were filtered through $0.22-\mu \mathrm{m}$ filters to ensure sterility. The pristine and modified sutures were sterilized with $75 \%$ ethanol and then immersed in Tris-buffered saline (TBS, $\mathrm{pH}=7.2$ ) containing $20 \mathrm{mg} / \mathrm{mL}$ fibrinogen and recombinant human platelet-derived growth factor-BB (PDGF) at varying concentrations $(0.05,0.1,0.2,1,3,10$ $\mu \mathrm{g} / \mathrm{mL}$ ) overnight at $4{ }^{\circ} \mathrm{C}$. The sutures loaded with fibrinogen and PDGF were then soaked in TBS containing $2 \mathrm{U} / \mathrm{mL}$ thrombin, $40 \mathrm{mM} \mathrm{CaCl}$, and the same concentration of PDGF used in the previous step at room temperature for $2 \mathrm{~h}$. The samples were stored in a sterile tube at $4{ }^{\circ} \mathrm{C}$ prior to further use. We used both small dye molecules (Rhodamine B) and proteins (FITC-labeled bovine serum albumin, BSA) to evaluate the loading capacity of the sutures, the loading procedures of which were the same as PDGF. Laser confocal fluorescence microscopy (Zeiss LSM 700) was used to resolve the distribution of the dyes and dye-labeled proteins in each suture.

Quantification of PDGF Release. Different groups of PDGF/fibrin/sutures (porous suture with $0.05,0.1,1,3$, and $10 \mu \mathrm{g} / \mathrm{mL}$ PDGF, $\mathrm{n}=3$ and pristine suture with $10 \mu \mathrm{g} / \mathrm{mL}$ PDGF, $\mathrm{n}=3$ per group) with a length of $3 \mathrm{~cm}$ each were incubated in $0.2 \mathrm{~mL}$ of PBS at $37^{\circ} \mathrm{C}$ and an aliquot of the solution 
was collected at each time point. After each collection, $0.2 \mathrm{~mL}$ of fresh PBS was added to retain the solution at a fixed total volume. The collected aliquots were stored at $-20^{\circ} \mathrm{C}$ before the amount of PDGF from each sample was quantified using an enzyme-linked immunosorbent assay (ELISA). The absorbance was read with a microplate reader (Synergy H4 Multi-Mode Plate Reader, Biotek). The concentration of PDGF from each sample was determined from a calibration curve derived from PDGF solutions with known concentrations.

Cell Culture and Live/Dead Staining. Human mesenchymal stem cells (hMSCs) were cultured in basal medium containing low glucose Dulbecco's Modified Eagle Media, supplemented with 10\% fetal bovine serum. Live/Dead staining of hMSCs on pristine suture, modified suture and $10 \mu \mathrm{g} / \mathrm{mL}$ PDGF-loaded porous suture using a Live/Dead staining kit (Invitrogen). After 72 hours, the culture medium was removed and the samples were washed gently with Dulbecco's Phosphate-Buffered Saline (DPBS). Then, $500 \mu \mathrm{L}$ of Live/Dead stain was added per well, and incubated for $30 \mathrm{~min}$ at $25^{\circ} \mathrm{C}$. Finally, the samples were washed with PBS and observed using a fluorescence microscope (DMI $6000 \mathrm{~B}$, Leica) at excitation wavelengths of $488 \mathrm{~nm}$ (green) and 533nm (red).

Statistics. The data from mechanical testing were analyzed using Student's t-tests in Microsoft Excel. Cell proliferation results were compared using two-way analysis of variance test (ANOVA) in GraphPad Instat software (GraphPad Software Inc.). Statistical significance was set at $p<0.05$.
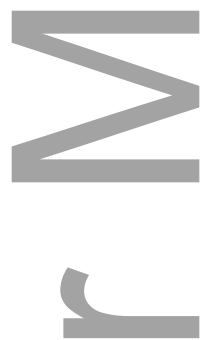

\section{References}

[1] M. T. Rodrigues, R. L. Reis, M. E. Gomes, J. Tissue Eng. Regen. Med. 2013, 7, 673.

[2] R. H. Gelberman, J. S. Vandeberg, P. R. Manske, W. H. Akeson, J. Hand Surg. Am. 1985, 10, 776.

[3] T. Molloy, Y. Wang, G. Murrell, Sports Med. 2003, 33, 381.

[4] S. Thomopoulos, R. Das, M. J. Silva, S. Sakiyama-Elbert, F. L. Harwood, E. Zampiakis, H. M. Kim, D. Amiel, R. H. Gelberman, J. Orthop. Res. 2009, 27, 1209.

[5] S. Thomopoulos, H. M. Kim, R. Das, M. J. Silva, S. Sakiyama-Elbert, D. Amiel, R. H. Gelberman, J. Bone Joint Surg. Am. 2010, 92, 2285.

[6] R. H. Gelberman, S. Thomopoulos, S. E. Sakiyama-Elbert, R. Das, M. J. Silva, J. Hand Surg. Am. 2007, 32, 373.

This article is protected by copyright. All rights reserved. 
[7] Y. Li, K. N. Kumar, J. M. Dabkowski, M. Corrigan, R. W. Scott, K. Nusslein, G. N. Tew, Langmuir 2012, 28, 12134.

[8] J. Schneider, A. Hapfelmeier, J. Fremd, P. Schenk, A. Obermeier, R. Burgkart, S. Forkl, S. Feihl, N. Wantia, B. Neu, M. Bajbouj, S. von Delius, R. M. Schmid, H. Algul, A. Weber, PLoS One 2014, 9, e110112.

[9] S. H. Cummings, D. A. Grande, C. K. Hee, H. K. Kestler, C. M. Roden, N. V. Shah, P. Razzano, D. M. Dines, N. O. Chahine, J. S. Dines, J. Tissue Eng. 2012, 3, 2041731412453577.

[10] A. Obermeier, J. Schneider, S. Wehner, F. D. Matl, M. Schieker, R. von Eisenhart-Rothe, A. Stemberger, R. Burgkart, PLoS One 2014, 9, e101426.

[11] T. F. Fuchs, C. Surke, R. Stange, S. Quandte, B. Wildemann, M. J. Raschke, G. Schmidmaier, Sci. Worlds. 2012, 2012.

[12] C. Uggen, J. Dines, M. McGarry, D. Grande, T. Lee, O. Limpisvasti, Arthroscopy 2010, 26, 1456.

[10] R. E.Tanenbaum, W. Shi, T. E. Johnson, S. T. Wester, Ophthal. Plast. Reconstr. Surg. 2014, 30, 110.

[14] H. Matsuzaki, M. A. Zaegel, R. H. Gelberman, M. J. Silva, J. Hand Surg. Am. 2008, 33, 709.

[15] M. Hattori, M. Saito, K. Okajima, K. Kamide, Polym. J. 1995, 27, 631.

[16] S. Samitsu, R. Zhang, X. Peng, M. R. Krishnan, Y. Fujii, I. Ichinose, Nat. Commun. 2013, 4, 2653

[17] S. H. Im, U. Jeong, Y. Xia, Nat. Mater. 2005, 4, 671.

[18] J. T. McCann, M. Marquez, Y. Xia, J. Am. Chem. Soc. 2006, 128, 1436.

[19] E. Lucarelli, A. Beccheroni, D. Donati, L. Sangiorgi, A. Cenacchi, A. M. Del Vento, C. Meotti, A. Z. Bertoja, R. Giardino, P. M. Fornasari, M. Mercuri, P. Picci, Biomaterials 2003, 24, 3095.

[20] J. O. Hollinger, C. E. Hart, S. N. Hirsch, S. Lynch, G. E. Friedlaender, J. Bone Joint Surg. Am. 2008, 90 Suppl 1, 48.

[21] M. A. Costa, C. Wu, B. V. Pham, A. K. S. Chong, H. M. Pham, J. Chang, Tissue Eng. 2006, 12, 1937.

[22] S. Thomopoulos, M. Zaegel, R. Das, F. L. Harwood, M. J. Silva, D. Amiel, S. Sakiyama-Elbert, R. H. Gelberman, J. Orthop. Res. 2007, 25, 1358.

[23] S. E. Sakiyama-Elbert, R. Das, R. H. Gelberman, F. Harwood, D. Amiel, S. Thomopoulos, J. Hand Surg. Am. 2008, 33A, 1548.

[24] P. P. Spicer, A. G. Mikos, J. Control. Release 2010, 148, 49.

[25] S. Sahoo, S. L. Toh, J. C. Goh, Biomaterials 2010, 31, 2990. 
[26] C. N. Manning, A. G. Schwartz, W. Liu, J. Xie, N. Havlioglu, S. E. Sakiyama-Elbert, M. J. Silva, Y. Xia, R. H. Gelberman, S. Thomopoulos, Acta Biomater. 2013, 9, 6905.

[27] D. A. Osei, J. G. Stepan, R. P. Calfee, S. Thomopoulos, M. I. Boyer, R. Potter, R. H. Gelberman, J. Hand Surg. Am. 2014, 39, 262.
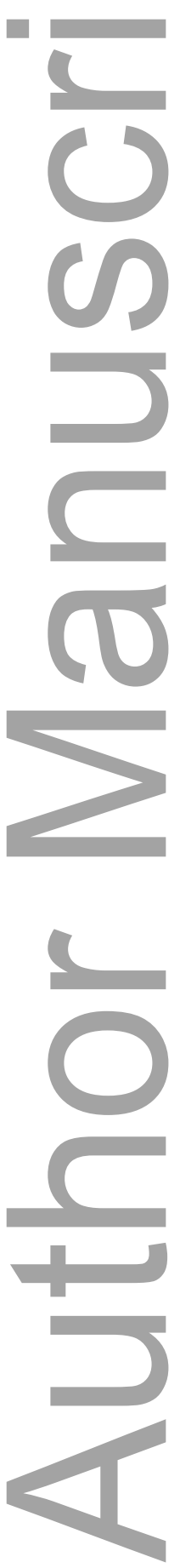

This article is protected by copyright. All rights reserved. 

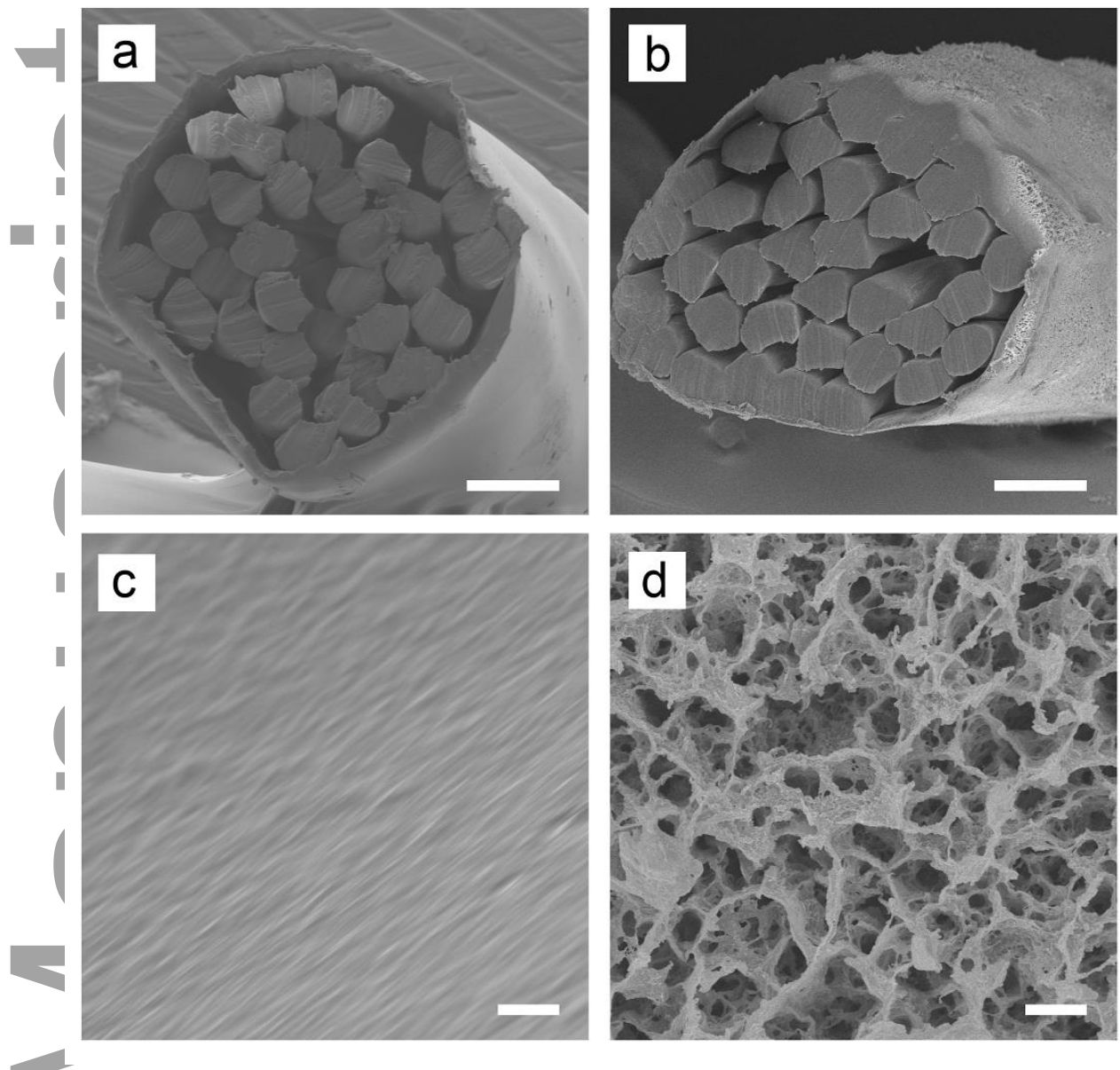

Figure 1. SEM images of the $(a, b)$ cross sections and $(c, d)$ side surfaces of the pristine $(a, c)$ and modified (b, d) sutures. Scale bars: $50 \mu \mathrm{m}$ in $(a, b)$ and $2 \mu \mathrm{m}$ in (c, d).

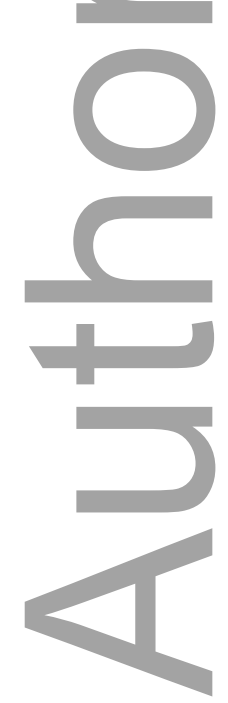

This article is protected by copyright. All rights reserved. 

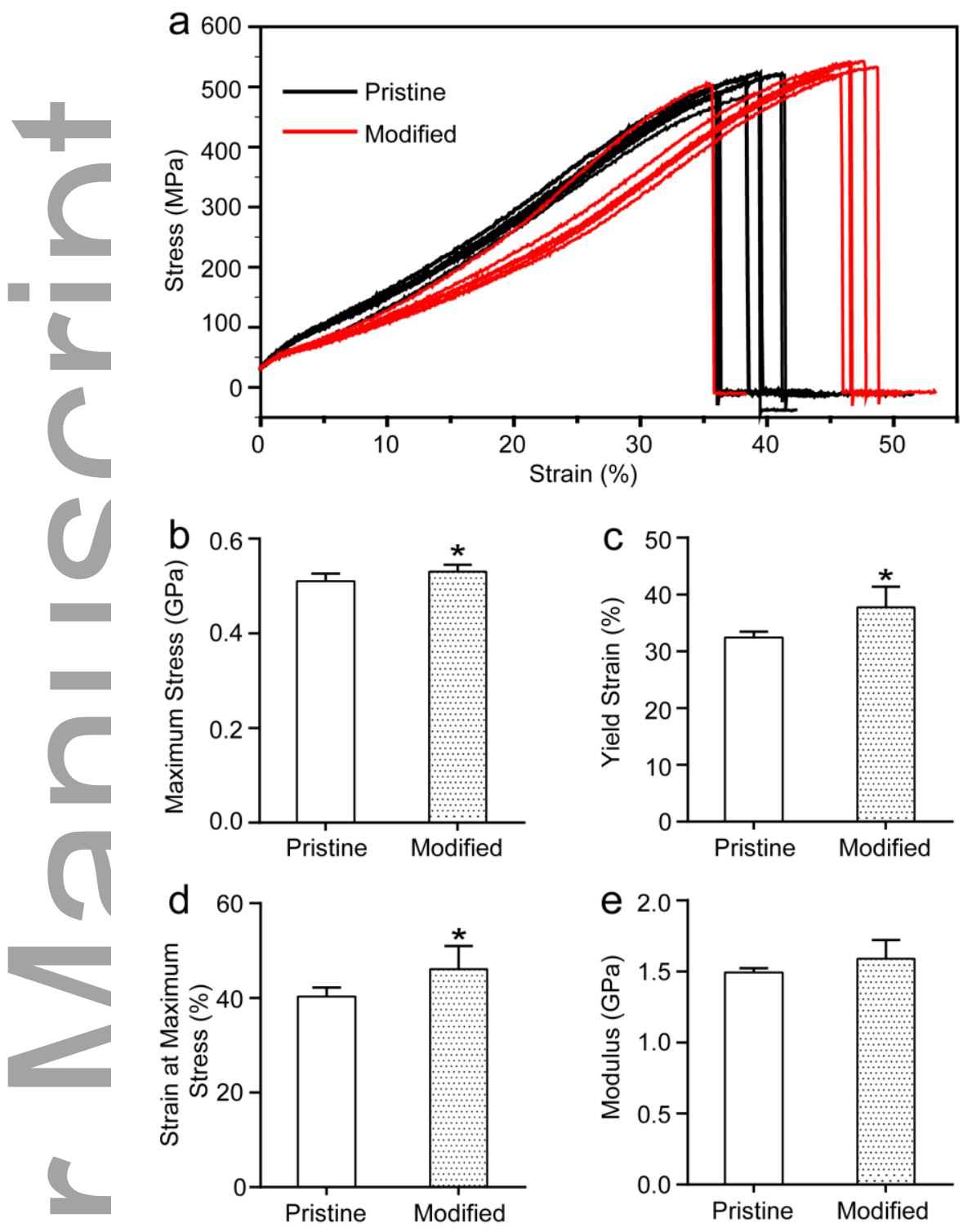

Figure 2. Tensile mechanical testing of the pristine and modified sutures: (a) Stress-strain behavior, (b) maximum stress, (c) yield strain, (d) strain at maximum stress, and (e) modulus. $\mathrm{N}=7$ for the pristine samples and $\mathrm{n}=6$ for the modified samples; ${ }^{*} \mathrm{p}<0.05$ (by t-test) indicates significant difference between the two types of samples.

This article is protected by copyright. All rights reserved. 


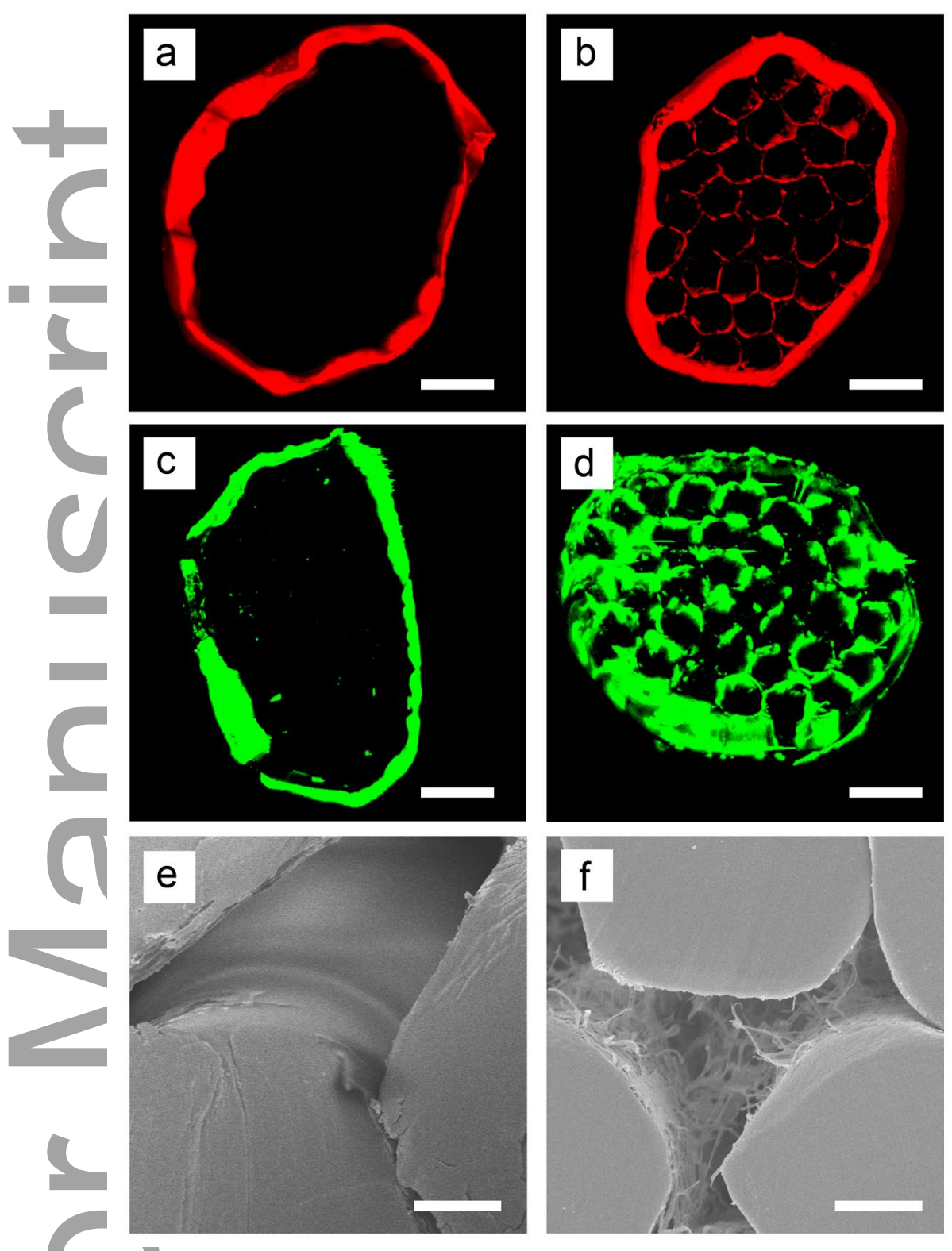

Figure 3. Sutures with porous sheaths showed a much higher loading capacity for both $(a, b)$ small molecules (Rhodamine B) and (c, d) proteins (FITC-labeled BSA), as indicated by (a-d) confocal fluorescence and $(e, f)$ scanning electron micrographs taken from the cross sections of $(a, c, e)$ pristine and $(c, d, f)$ modified sutures. The fibrin matrix and dye is evident in the voids among the inner filaments of the modified suture. In contrast, dye is nearly absent from the interior of the pristine suture. Scale bars: $50 \mu \mathrm{m}$ in (a-d) and $10 \mu \mathrm{m}$ in $(e, f)$.

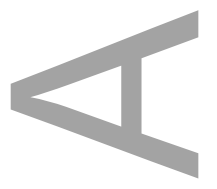

This article is protected by copyright. All rights reserved. 


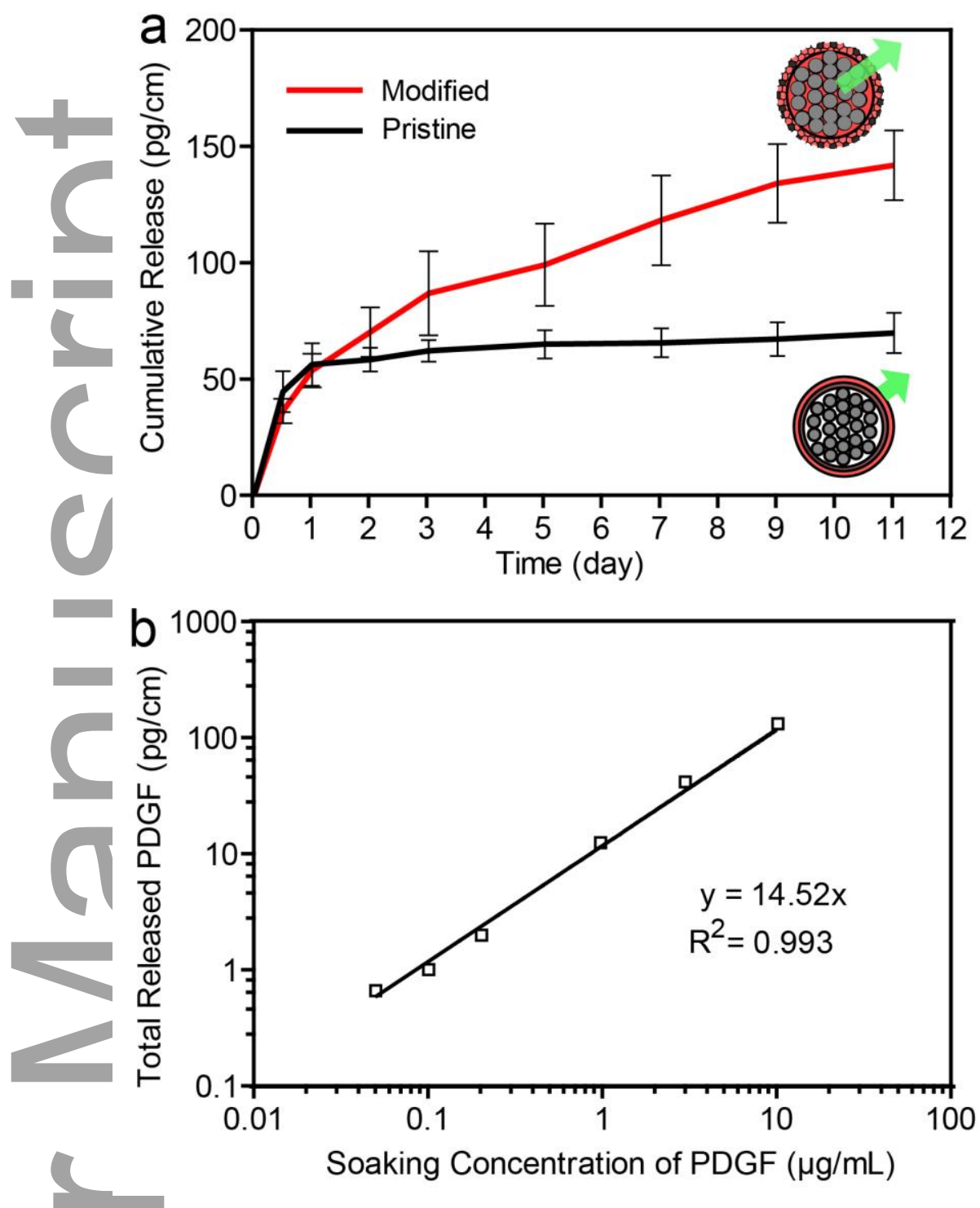

Figure 4. (a) Cumulative release of PDGF from the modified sutures incubated with PDGF at a concentration of $10 \mu \mathrm{g} / \mathrm{mL}(\mathrm{n}=3)$. The pristine sutures incubated with PDGF at a concentration of 10 $\mu \mathrm{g} / \mathrm{mL}$ served as a reference $(\mathrm{n}=3)$. (b) Correlation between the total amount of PDGF released from the modified sutures for 11 days and the concentration of PDGF used for the loading process (each point is represented by an average value from three individual measurements; $p<0.01$ ).

This article is protected by copyright. All rights reserved. 


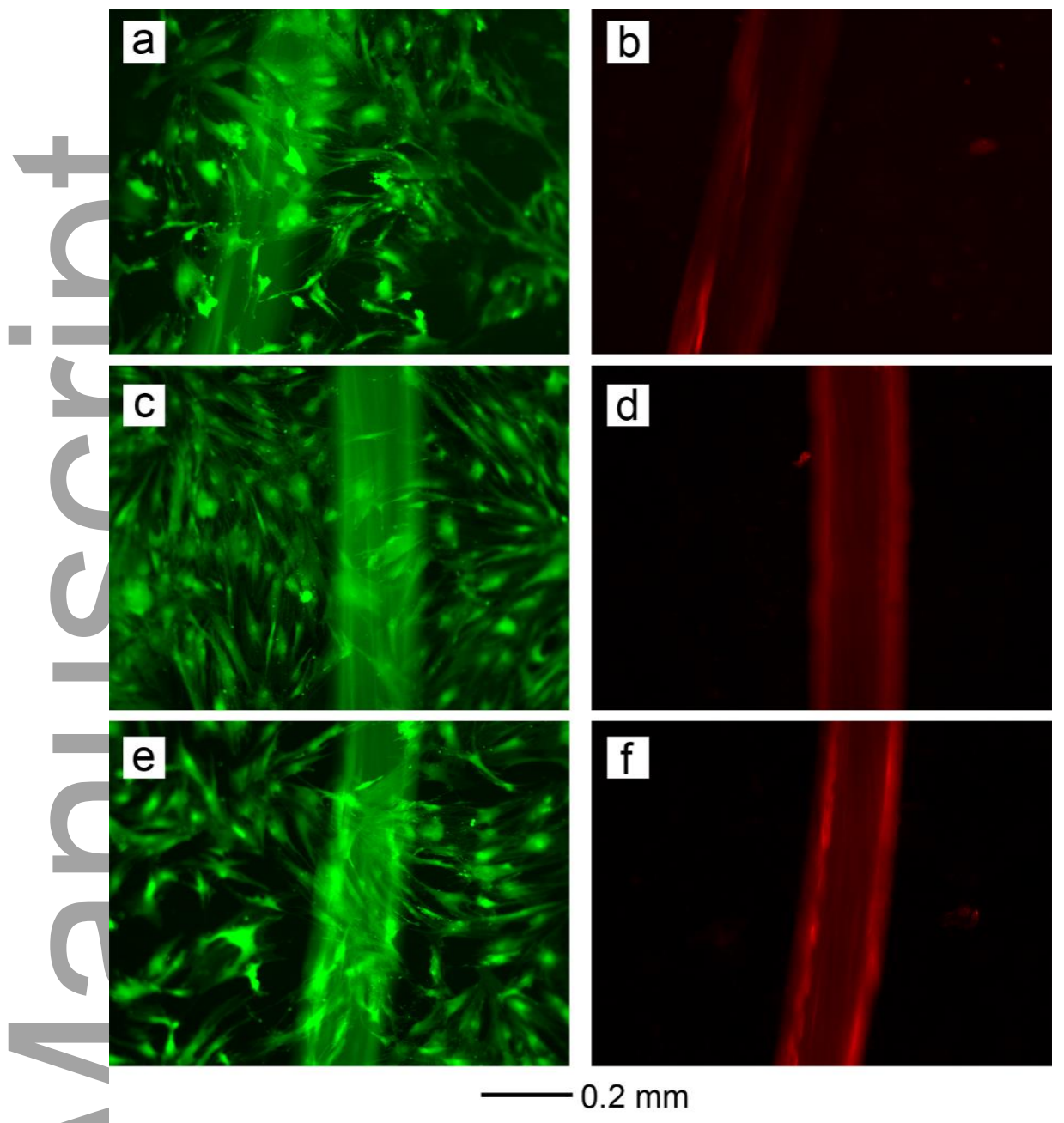

Figure 5. Live/Dead staining of hMSCs on the (a, b) pristine, (c, d) modified, and (e, f) PDGF-loaded porous suture after culture for $72 \mathrm{~h}$. The live and dead cells were stained green and red, respectively. Note that the suture material also emits red fluorescence under the same excitation light source. There were no dead cells (stained in red) seen, indicating that the sutures were nontoxic to hMSCs.

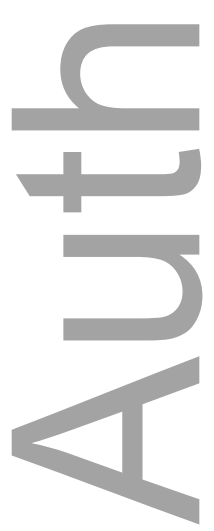

This article is protected by copyright. All rights reserved. 


\section{University Library}

\section{- M M N E R VA A gateway to Melbourne's research publications}

Minerva Access is the Institutional Repository of The University of Melbourne

Author/s:

Li, J;Linderman, SW;Zhu, C;Liu, H;Thomopoulos, S;Xia, Y

Title:

Surgical Sutures with Porous Sheaths for the Sustained Release of Growth Factors

Date:

2016-06-15

Citation:

Li, J., Linderman, S. W., Zhu, C., Liu, H., Thomopoulos, S. \& Xia, Y. (2016). Surgical Sutures with Porous Sheaths for the Sustained Release of Growth Factors. ADVANCED MATERIALS, 28 (23), pp.4620-4624. https://doi.org/10.1002/adma.201506242.

Persistent Link:

http://hdl.handle.net/11343/291148 